\title{
The role of astrocyte-mediated plasticity in neural circuit development and function
}

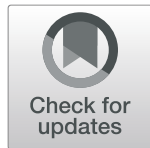

Nelson A. Perez-Catalan ${ }^{1,2}$ (D), Chris Q. Doe ${ }^{1}$ (D) and Sarah D. Ackerman ${ }^{*^{*}}$ (D)

\begin{abstract}
Neuronal networks are capable of undergoing rapid structural and functional changes called plasticity, which are essential for shaping circuit function during nervous system development. These changes range from short-term modifications on the order of milliseconds, to long-term rearrangement of neural architecture that could last for the lifetime of the organism. Neural plasticity is most prominent during development, yet also plays a critical role during memory formation, behavior, and disease. Therefore, it is essential to define and characterize the mechanisms underlying the onset, duration, and form of plasticity. Astrocytes, the most numerous glial cell type in the human nervous system, are integral elements of synapses and are components of a glial network that can coordinate neural activity at a circuit-wide level. Moreover, their arrival to the CNS during late embryogenesis correlates to the onset of sensory-evoked activity, making them an interesting target for circuit plasticity studies. Technological advancements in the last decade have uncovered astrocytes as prominent regulators of circuit assembly and function. Here, we provide a brief historical perspective on our understanding of astrocytes in the nervous system, and review the latest advances on the role of astroglia in regulating circuit plasticity and function during nervous system development and homeostasis.
\end{abstract}

Keywords: Astrocyte, Synapses, Circuits, Hebbian plasticity, Homeostatic plasticity, Gap junction

\section{Background}

Nervous system assembly requires precise coordination between the formation of millions of synapses and integration of these synapses into functional circuits. Failure to do so leads to significant life-altering neurodevelopmental and neurodegenerative disorders [1-5]. Between 2006 and 2008, approximately 15\% of children aged three to seventeen were affected by neurological disorders in the United States alone [6]; thus, understanding the mechanisms that regulate proper neural development will have a direct impact on human health.

Glial cells help coordinate synapse formation and circuit assembly. Additionally, they monitor, instruct, and support neuronal activity in mature circuits $[6,7]$.

\footnotetext{
* Correspondence: sarah.d.ackerman@gmail.com

${ }^{1}$ Institute of Neuroscience, Howard Hughes Medical Institute, University of Oregon, Eugene, OR, USA

Full list of author information is available at the end of the article
}

Astrocytes, the most abundant subtype of glial cells in the central nervous system (CNS), are classically known for their roles in neurovascular coupling and metabolic support of neurons during homeostasis [8]. In the mature nervous system, astrocytes directly contact the neuronal soma, dendrites, spines, and presynaptic terminals (Fig. 1) [9], thus they are uniquely poised to regulate neuronal function.

\section{Astrocyte heterogeneity in the nervous system}

Astrocytes have been described as a homogenous population of cells since their discovery [10], yet, a growing body of evidence now suggests that astrocytes are highly diverse in their morphology, gene expression profiles, and functionality [11-16]. For example, in the developing vertebrate spinal cord, differential expression of morphogens from the dorsal and ventral poles generates

(c) The Author(s). 2021 Open Access This article is licensed under a Creative Commons Attribution 4.0 International License, which permits use, sharing, adaptation, distribution and reproduction in any medium or format, as long as you give appropriate credit to the original author(s) and the source, provide a link to the Creative Commons licence, and indicate if changes were made. The images or other third party material in this article are included in the article's Creative Commons licence, unless indicated otherwise in a credit line to the material. If material is not included in the article's Creative Commons licence and your intended use is not permitted by statutory regulation or exceeds the permitted use, you will need to obtain permission directly from the copyright holder. To view a copy of this licence, visit http://creativecommons.org/licenses/by/4.0/. The Creative Commons Public Domain Dedication waiver (http://creativecommons.org/publicdomain/zero/1.0/) applies to the data made available in this article, unless otherwise stated in a credit line to the data. 


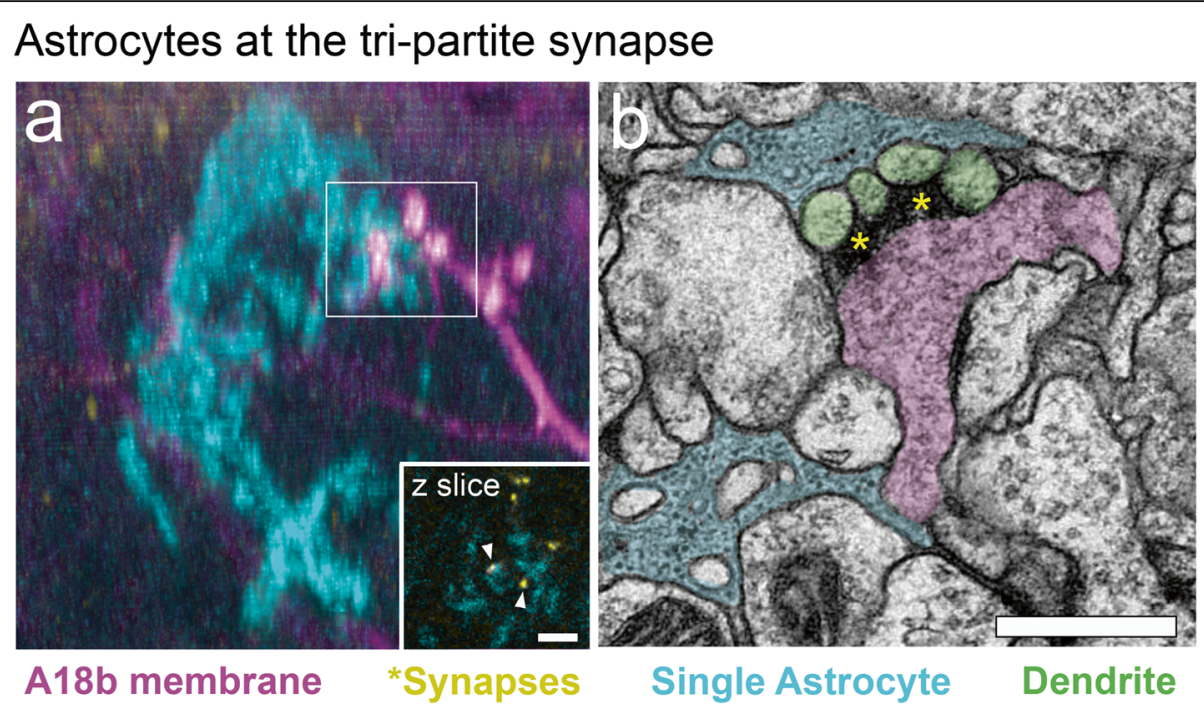

Fig. 1 Astrocytes locally support neuronal synapses.a Light microscopy image of single astrocyte (cyan) contacting the pre-synaptic membrane of the Drosophila A18b neuron (magenta), with pre-synapses highlighted in the inset (yellow). First instar larva. Genotype: A18b (94E10-lexA; 8xlexAop-2xBrp-short::cherry; lexAop-myr::GFP), astrocyte (25h07-gal4; hs-FLPG5;:; 10xUAS(FRT.stop)myr::smGdP-HA, 10xUAS(FRT.stop)myr::SmGdP-V5, 10xUAS-(FRT.stop)myr::smGdP-FLAG). Scale bar, $200 \mathrm{~nm}$. b TEM image showing a single astrocyte (cyan) contacting the pre-synaptic membrane of the A18b neuron (magenta), and the post-synaptic membrane of an A27a neuron (green) with synapses highlighted (yellow asterisks). Genotype: wild type. First instar larva. Scale bar, $500 \mathrm{~nm}$

neurons belonging to eleven distinct functional domains organized along the dorsal-ventral axis [17]. Astrocytes tile throughout the vertebrate spinal cord, and interestingly, spinal cord astrocytes also show domain-specific expression profiles, leading to the hypothesis that domain-specific astrocytes represent subclasses. Indeed, a recent report found that depletion or mutation of astrocytes from the pMN domain of the mouse spinal cord disrupted sensorimotor circuit formation and maintenance, and that astrocytes from neighboring domains do not repopulate the region to compensate [12, 13]. More recently, in situ single-cell gene expression analyses of cortical astrocytes found laminar organization of astrocyte transcriptomes, as well as markers for superficial, mid and deep astroglial populations in adult mouse and human cortex [18]. Disruption of neuronal differentiation in murine cortical layers L2-4 resulted in aberrant astrocyte organization in the superficial layers. Moreover, inversion of neuronal layers in the cortex at postnatal day 14 (P14) resulted in similarly upturned astrocytic marker expression. Together, these data demonstrate that astrocytes show region-specific expression and function [19]. It remains to be tested whether these changes are astrocyte-intrinsic, or whether the neuronal microenvironment resolves local astroglial identity.

\section{Astrocyte expansion coincides with synapse development} Recent data suggest that astrocytes are also critical regulators of nervous system development $[8,20]$. Indeed, studies from multiple model systems suggest that the expansion of astrocytic membrane domains occurs in tandem with the birth and refinement of synapses within individual circuits, including visual processing, attention, memory, and motor control pathways [21-28]. Astrocytes extend fine processes to establish non-overlapping territories after the first postnatal week in the developing mouse cortex, coincident with synaptogenesis [29]. The timing of astrocyte migration and expansion in the developing spinal cord occurs earlier in rodents, ranging from late prenatal stages to postnatal day seven [30]. Similarly, astrocytes extend processes into the Drosophila ventral nerve cord (analogous to the vertebrate spinal cord) during the final stage of embryogenesis [31], and by 6 days post-fertilization in the developing zebrafish spinal cord [32]. In humans, astrocytes are born in late fetal stages [33]. Although studies of human astrocyte development are challenging and a precise timecourse of human astrocyte-synapse association has yet to be done $[34,35]$ a single cortical human astrocyte can extend processes from the soma that gradually ensheath upwards of two million individual synapses [36]. It is noteworthy to mention that human astrocytes are larger, more structurally complex, and more diverse than astrocytes in any other chordates assessed to date [14, 36-39]. In each case, the expansion of astrocytic membranes into the neuropil occurs alongside synaptogenesis. Together, these studies intimated that astrocyte-derived cues could influence synapse development, and vice versa. 


\section{Astrocyte regulation of synapse number}

Given the relatively late timecourse of astrogenesis during nervous system development, astrocytes are not present to regulate embryonic waves of neurogenesis and axon outgrowth. Though outside the scope of this review, note that astrocytes do form part of the neurogenic niche that regulates adult neurogenesis (reviewed in [40]), and that reactive astrocytes regulate axon regrowth and recovery after nervous system injury [41]. During early postnatal development, astrocytes elaborate their fine processes concurrent with synaptogenesis. The timing of astrocyte arrival in the CNS, and their strategic positioning of peri-synaptic processes, make astrocytes an attractive candidate to promote assembly of neurons into neural circuits. We now appreciate that these roles include, but are not limited to, structural and functional synaptogenesis [21, 25, 26, 42], synapse pruning [43, 44], and synapse maintenance [13].

\section{Astrocytes in synaptogenesis}

A role for astrocytes in synaptogenesis was first defined in the lab of Dr. Ben Barres by taking advantage of mouse retinal ganglion cell (RGC) culturing systems. These pioneering studies demonstrated that addition of astrocytes to neuronal cultures was sufficient to promote synapse formation and spontaneous activity of RGC neurons, which are largely inactive in the absence of glial support $[28,45,46]$. A similar role for astrocytes in promoting synaptogenesis using rat RGC microcultures was described shortly thereafter [47], and more recently in cultured human cerebral cortical spheroids [48]. Together, these data provide direct cross-species evidence that astrocytes are able to directly promote circuit development and function in vitro. Genetic access to astrocytes during circuit assembly was not available until recently [49-53], yet these advances have rapidly expanded our understanding of the contribution of astrocytes to circuit development. Advances on invertebrate and vertebrate in vivo animal models demonstrate that astrocytes are regulators of neural circuit assembly in $C$. elegans [54, 55]; Drosophila [56, 57]; feline [58]; Xenopus [59]; rodent $[8,25,28,47]$; and human $[60,61]$.

Over the last decade, we have greatly expanded our understanding of the molecular mechanisms by which astrocytes regulate synaptogenesis. Astrocyte-derived (secreted and membrane bound) synaptogenic and antisynaptogenic cues dynamically interact to finely tune synapse number during neural circuit assembly [8, 62]. As these pathways have been extensively covered elsewhere $[8,63]$, here we focus specifically on Hevin and SPARC, which are essential for the generation of functional synapses during mammalian nervous system development, and also regulate synapse plasticity (discussed below) [26]. These proteins are of additional interest given that the upregulation of their expression profiles has been linked to neurodevelopmental disorders [64] and reactive astrogliosis in adults [65-67]. The matricellular protein Hevin is secreted by astrocytes localized to excitatory CNS synapses throughout the organism's life, and peaks in its expression during synaptogenesis and following CNS injury [14, 67-69]. Extensive studies of retinocollicular and thalamocortical synapse development have demonstrated that Hevin is required for the formation and maturation of glutamatergic synapses $[26,27,70]$. In the latter case, Hevin refines thalamic presynaptic inputs onto cortical dendrites by bridging pre-synaptic Neurexin- $1 \alpha$ to dendritic Neuroligin-1B, and loss of Hevin causes a reduction of mature glutamatergic synapses [27]. Astrocytes also produce SPARC (Secreted Protein Acidic and Rich in Cysteine), which acts as a competitive inhibitor to antagonize Hevin-induced synaptogenesis. According, while Hevin null mice show decreased numbers of excitatory synapses in the superior colliculus, SPARC KO mice show enhanced synaptogenesis in the same brain region at P14 [26]. Interestingly, SPARC does not inhibit excitatory synaptogenesis induced by astrocyte-derived thrombospondins, but is a specific antagonist of Hevin. Because these proteins are not known to physically interact, it remains to be seen how Hevin and SPARC function together to tune synapse number in vivo [26]. More recently, a novel in vivo enzymatic assay defined a proteome for extracellular astrocyte-neuron junctions in the primary visual cortex (V1 cortex) and found that astrocytic Neuronal Cell Adhesion Molecule (NRCAM) binds to NRCAM-gephyrin complexes on postsynaptic neurons to induce the formation and function of inhibitory GABAergic synapses, with only minor effects on excitatory synapses [71]. Together, these results identify a direct role for astrocytes in the control of excitatory and inhibitory synapse assembly and maturation in vivo, while also displaying the heterogeneity of astroglial cues depending on the synapse subtype.

\section{Astrocytes in synapse pruning}

Overproduction of synapses and their subsequent experience-dependent elimination is critical for refinement of neuronal circuits during development [72]. This is especially well-characterized during ocular dominance plasticity (discussed further below), and during Drosophila circuit rewiring in metamorphosis and regeneration $[43,59]$. In 2013, Chung et al., demonstrated that astrocytes and microglia participate in synapse elimination via two activity-dependent phagocytic receptors, MEGF10 and MERTK, which trigger engulfment of excitatory and inhibitory synapses in the developing mouse visual system (Fig. 2c). Loss of MEGF10 in mouse results in a failure to refine retinogeniculate connections in the 


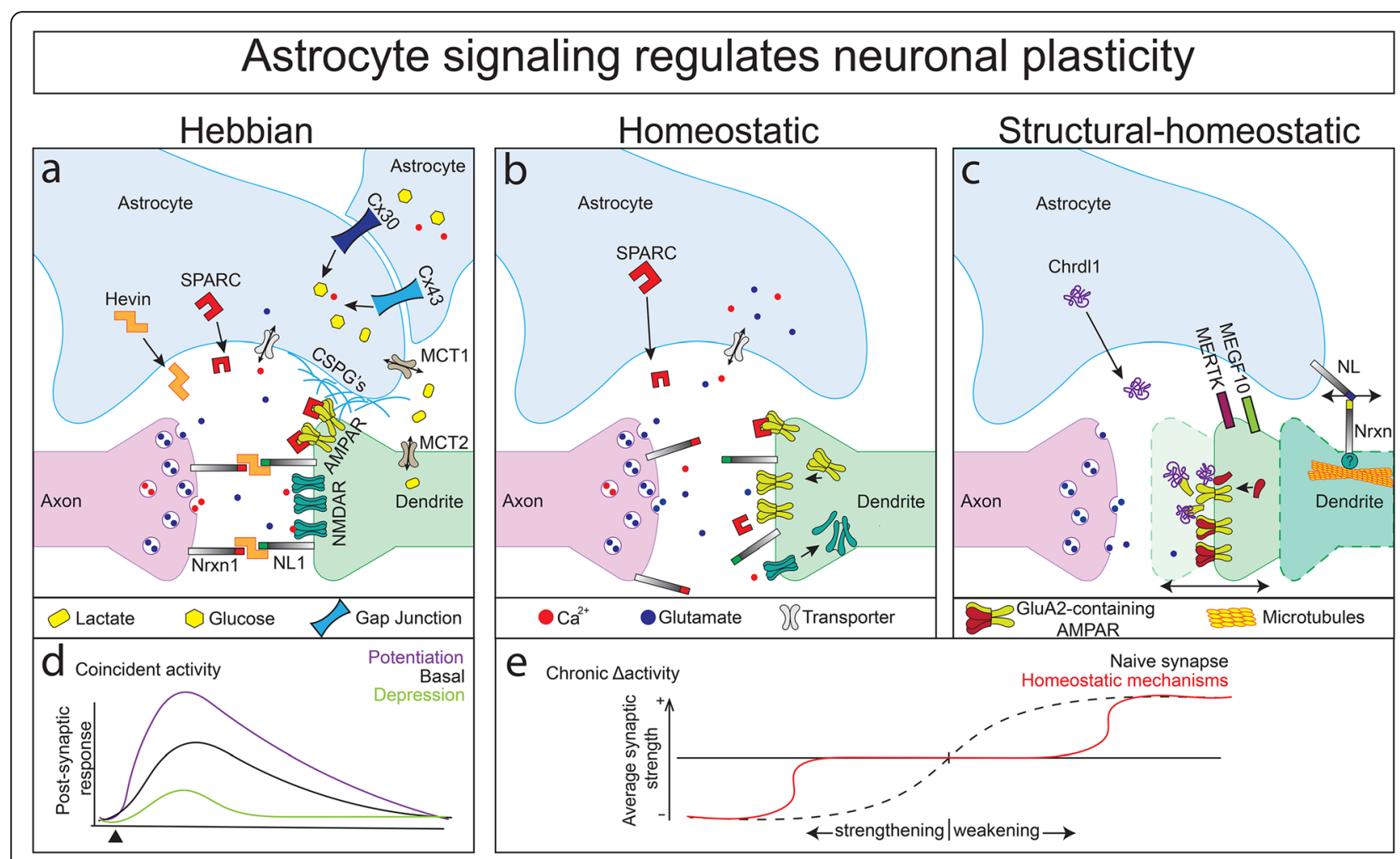

Fig. 2 Select mechanisms for astrocyte-induced plasticity. a Hebbian plasticity. Recruitment of NMDA receptors is mediated by astrocyte-derived Hevin and the cell adhesion molecules Neuroligin-1 (NL1) and Neurexin-1 (Nrxn1) during the ocular dominance plasticity critical period. Astrocyte chondroitin sulfate proteoglycans (CSPGs) and SPARC stabilize AMPA postsynaptic receptors. Astrocyte gap junction proteins Connexins 30 and 43 regulate metabolite transport through monocarboxylate transporters (MCT1/2) between astrocytes and neurons in an activity-dependent manner to facilitate plasticity. $\mathbf{b}$ Homeostatic plasticity. Astrocyte-derived SPARC limits aggregation of AMPA receptors to facilitate synaptic scaling in response to chronic silencing. Additionally, receptors and transporters located in the astrocytic membrane monitor neuronal $\mathrm{Ca}^{2+}$ transients and release of neurotransmitters, resulting in gliotransmitter release. c Structural-homeostatic plasticity. Astrocyte-secreted Chrdl1 restricts neuronal plasticity by directly switching postsynaptic neurotransmitter receptor identity. Astrocyte-derived Neuroligin (NL) binds dendritic Neurexin (Nrxn) to mediate the closure of critical periods by stabilizing dendrite microtubule populations. Synapse elimination is driven by neuronal activity, and is regulated by astroglial MERTK and MEGF10. $\mathbf{d}$ Repeated excitatory postsynaptic potentials evoke more robust synaptic activity in potentiated circuits over time. Conversely, synapses targeted by long term depression display lower levels of excitability

following stimulation. e Homeostatic mechanisms decrease the difference between synaptic input and output by bidirectionally adjusting the probability of transmitting an action potential postsynaptically

developing visual system, resulting in ectopic synapses with reduced functionality [43]. Similarly, the Drosophila homolog of MEGF10, Draper, is necessary for clearance of axons during injury and during circuit remodeling $[44,73,74]$. A feature of the adult CNS is its ability to engage in activity-dependent synaptic plasticity during learning and memory [75]. Strikingly, MEGF10 and MERTK-dependent synaptic engulfment by astrocytes continues through adulthood in both murine and human cortical layers, which may contribute to learning, memory, and disease [43, 76, 77]. A recent report in Drosophila discovered that during a critical period of brain development in young adults, the extracellular domain of the amyloid precursor protein-like (APPL, homologous to human APP) regulates glial expression of Draper and clearance of neuronal debris after injury [78]. It will be interesting to test whether APPL/APP also regulates developmental pruning of synapses. Thus, the number of synapses on a neuron is not exclusively an intrinsic property but is heavily regulated by glial signals.

\section{Astrocytes tune synapse function and synaptic plasticity}

The establishment of functional neuronal circuits does not only depend on early synaptogenic and pruning processes. To achieve precise CNS wiring, the developing nervous system must be able to adapt to the onset of neural activity, which can induce extensive, activitydependent functional and structural remodeling of mature synapses [79]. Also known as plasticity, these restructuring events are usually driven by the arrival of environmental stimuli via sensory afferents $[80,81]$. The progression from immature to functionally effective 
neuronal circuits that drive robust behavior is dependent on careful regulation of short- and long-term remodeling events. These events are strongly enriched during developmental windows called critical periods [80, 82]. If changes in synaptic strength are not carefully regulated, the activity passing through a given neuronal circuit could increase or decrease unchecked, resulting in abnormal activity patterns, the loss of sensitivity for synaptic partners, or excitotoxicity [79, 83, 84].

Functional and structural modifications to synapse and circuit function are generally categorized as either $\mathrm{Heb}$ bian or homeostatic plasticity (Fig. 2a-c). During Hebbian plasticity, coincident activity at pre- and postsynaptic sites causes modifications that alter synaptic efficacy through a positive feedback loop (Fig. 2d). The most widely studied form of Hebbian plasticity is longterm potentiation (LTP), which underlies long-term memory [79, 85-87]. Hebbian plasticity usually occurs at single synapse scale rather than circuit-wide scale, where an increase in presynaptic firing increases the probability of a further increase in postsynaptic gain [79, 88]. Conversely, homeostatic plasticity is a negative feedback mechanism that is activated in response to chronic changes to activity and serves to prevent runaway excitation/inhibition in response to Hebbian plasticity (Fig. 2e). Although homeostatic plasticity can function on individual synapses $[89,89]$, it also functions on the scale of whole neurites, neurons, and even to balance levels of activity through an entire circuit via functional and structural remodeling [88, 90-93]. The changes that arise from these dynamic remodeling events can have profound effects on circuit function, behavior, and human health [82], yet the developmental mechanisms that promote or restrict plasticity are not yet fully understood at the cellular or molecular level.

\section{Astrocytes regulate hebbian plasticity, one synapse at a time}

Following the discovery of Hebbian plasticity over half a century ago [85], many different forms of remodeling have been identified, including both local (synaptic) and circuit-wide [79, 80, 86]. However, studies of neurons alone have failed to reveal how circuit plasticity is established and circuit balance is maintained. As mentioned above, RGCs cultured in the presence of astrocytes show elevated neuronal activity [46]. Recent advancements in microscopy and genetic strategies for monitoring glial cell populations have led to a new awareness for how astrocytic networks are strategically arranged to support and modify synaptic activity $[47,94,95]$.

In the mammalian CNS, glutamate triggers ion flow through N-methyl-D-aspartate receptors (NMDARs) on postsynaptic membranes to power excitatory neurotransmission [96]. Repeated stimulation of sensory and learning pathways (such as those in the hippocampus) can enhance recruitment of NMDARs to the postsynaptic terminal, thereby increasing the efficacy of long-term synaptic transmission (e.g. LTP) [97, 98]. In addition, the concentration of $\alpha$-amino-3-hydroxy-5-methyl-4-isoxazolepropionic receptors (AMPARs) on postsynaptic membranes can alter short-term synaptic plasticity [99]. As aforementioned, astrocytes secrete the matricellular protein Hevin, which increases the number and size of excitatory synapses in RGC cultures and in vivo during development of the visual system [26, 27, 70]. Recent studies revealed an additional role for Hevin in neuronal plasticity. During ocular dominance plasticity (ODP), monocular deprivation weakens synapses downstream of the closed eye, while cortical connections downstream of the open eye are coincidently strengthened [58, 100-102]. This process is dependent on the differential recruitment of post-synaptic NMDARs [101, 103-105]. Astrocytederived Hevin organizes presynaptic Neurexins and postsynaptic Neuroligins (binding partners), thereby aligning the pre-synaptic neurotransmitter release machinery with post-synaptic NMDARs during the ODP critical period (Fig. 2a) [27, 106]. Accordingly, Hevin null mice exhibit reduced ODP, which can be rescued upon viral delivery of Hevin to astrocytes [27]. Interestingly, though Hevin and SPARC have opposing functions in synaptogenesis, synaptic plasticity (LTP) is also reduced in the hippocampus of SPARC null mice. Reduced LTP in SPARC null animals is not the result of decreased NMDAR localization, but rather increased levels of AMPARs on postsynaptic membranes and enhanced baseline activity of these synapses [107]. These data suggest that during developmental plasticity, Hevin and SPARC function together to fine-tune the ratio of NMDARs to AMPARs to facilitate LTP. Overall, these data demonstrate that astrocytes modulate synaptic strength by regulating post- and presynaptic receptor composition.

\section{Astrocyte tiling and synaptic transmission}

Bidirectional communication between astrocytes and synaptic terminals is critical for the establishment and maintenance of neuronal transmission $[8,106]$. A property of astrocytes that expands the complexity of these interactions is the capacity of a single astrocyte to associate with millions of synapses within an expanded glial network. This network is generated by gap junctions (GJs) that allow neighboring astrocytes to tile with one another, yet maintain non-overlapping territories [108-110]. GJs are intercellular channels that integrate astrocytes into functional syncytia, which facilitate signaling and transport of metabolites between neuronal and non-neuronal tissues [111, 112]. The GJ proteins connexin 30 (Cx30) and connexin 43 (Cx43) are highly expressed in astrocytes $[69,113]$, and act to shuttle glucose and its metabolites (lactate) from 
astrocytes to neurons in an activity-dependent manner (Fig. 2a) $[111,114,115]$. In the absence of astroglial Cx30 and $\mathrm{Cx} 43$, astrocyte-dependent glutamate recycling and potassium buffering at the synapse is impaired. This results in enhanced excitability at hippocampal CA1 Schaffer collateral synapses due to increased levels of AMPARs [94]. Interestingly, analysis of synapse numbers on CA1 neurons of $C \times 30^{-/-} C \times 43^{-/-}$mice revealed that while the overall number of synapses remains unchanged in the absence of GJs, the pool of silent synapses was significantly decreased. This led to defects in Hebbian plasticity, including suppressed LTP and increased occurrences of long-term depression. Disruptions to astrocyte GJ proteins have been linked to impairments in LTP during memory allocation and stress in the mammalian hippocampus [115-117]; thus, GJ-dependent astrocyte communication is critical for developmental learning and behavior.

\section{Astrocyte-derived extracellular matrix modifies synaptic plasticity}

Finally, astrocytes may influence synaptic efficacy through modulation of the extracellular environment [118]. Chondroitin sulfate proteoglycans (CSPGs) are glycosylated, extracellular matrix proteins secreted by both neurons and glia that form integral components of perineuronal nets (PNNs). PNNs are lattice-like aggregates of CSPGs surrounding neuronal processes [119]. PNNs emerge in concert with the arrival of astrocytes during late postnatal development, corresponding with the closure of critical periods of experience-dependent plasticity [82, 120]. CSPGs act as lateral diffusion barriers for AMPARs, and can therefore facilitate post-synaptic receptor composition to modulate short-term synaptic plasticity (Fig. 2a) [121]. It was recently shown that removal of PNNs from the mouse deep cerebellar nuclei increased synaptic plasticity and improved active learning during eyeblink conditioning, a form of motor learning. Conversely, loss of PNNs inhibited the formation of eyeblink-associative memories [122]. Although astrocytes express a variety of CSPGs during nervous system development [14, 69] and following injury [123-125], the relative contribution of astrocyte to neuronderived ECM for circuit development and plasticity remains poorly defined [126, 127]. An important open question is whether astrocytic CSPGs modulate AMPAR aggregation in vivo during circuit assembly. In addition, it remains unknown whether astrocyte-derived and neuronal-derived CSPGs trigger different signaling cascades. This is especially critical to determine because altered CSPG signaling is linked to poor outcomes in injury and disease [123-125, 128-131].

\section{Astrocytes are key regulators of homeostatic plasticity, from synapses to circuits}

Homeostatic plasticity arises in response to prolonged changes in network activity, shifting the balance away from extreme excitation (E) or inhibition (I) to maintain
E/I balance. Thus, a neuron can preserve its ability to respond to activity via Hebbian plasticity by maintaining a functional state of excitability [132]. This form of plasticity was first theorized to exist as a "normalizing" force in mathematical models of circuit function [133-135], as the technology to detect, characterize, and confirm homeostatic plasticity was not available until much later [136-141]. Homeostatic plasticity has the capacity to modify multiple substrates within neural circuits. Synaptic scaling is a homeostatic mechanism that alters the strength of individual synapses, which can modify the activity and function of neurotransmission for a single neuron [132, 142]. Synaptic scaling is a modification to the number of AMPAR at the post-synaptic terminal, which can reduce synaptic strength and the probability of a postsynaptic potential. Modifications to neurotransmission through synaptic scaling can take place either by removing AMPARs locally at the terminal [143], or globally, by affecting the rate of transcription of AMPARs within a circuit [144]. Although several neuronal mechanisms for homeostatic plasticity have been defined [141], a looming question is to determine how this form of plasticity is regulated at the circuit level. The juxtaposition of synapses and perisynaptic processes of astrocytes (Fig. 1) makes them a great target to study regulation of homeostatic plasticity [88, 145].

We now understand that astrocytes secrete a number of proteins that modulate homeostatic plasticity at the synaptic and circuit level. A well-documented example is SPARC [146, 147]. As noted above, analysis of cultured hippocampal slices from astrocyte-specific SPARC knock-out mice revealed increased numbers of postsynaptic GluR2 receptor subunits, which caused an ectopic accumulation of postsynaptic surface AMPARs and impaired LTP following high frequency stimulation [107]. Accordingly, loss of SPARC inhibits synaptic scaling following activity deprivation by TTX (Fig. 2c) [107]. These data demonstrate that astrocytes can co-opt the same signaling pathways to regulate both Hebbian and homeostatic plasticity during circuit assembly.

During critical periods, activity across circuits can also alter neuronal architecture, ranging from retraction/extension of individual synaptic elements to modifications to dendrites and axons. This form of plasticity, also known as homeostatic structural plasticity, can drastically affect the probability of forming synapses between neighboring neurons by physically increasing or decreasing membrane space [88, 90, 92, 93, 148, 149]. Recent work has defined important roles for astrocytes in homeostatic structural plasticity $[42,93,150]$. In the CNS, astrocyte-secreted Chordin like-1 (Chrdl1) was shown to regulate the switch from AMPAR to GluA2containing synapses in the developing mouse cortex [42]. Moreover, in a monocular enucleation model of 
ocular dominance homeostatic plasticity (reviewed in [151]), Chrdl1 knock-out resulted in ectopic synaptic remodeling events, suggesting that astrocytes use Chrdl1 to restrict neuronal plasticity (Fig. 2c). Excitingly, a recent report demonstrated that astrocytes close a critical period of motor dendrite remodeling in the Drosophila CNS via astrocyte Neuroligin to motor neuron Neurexin signaling (Fig. 2c) [93]. Importantly, this study pinpoints astrocytes as a putative target in critical perioddependent neurodevelopmental disorders [152].

\section{Astrocytes shape neuronal signaling}

Although astrocytes themselves are not electrically excitable, astrocytes measure local synaptic activity via metabotropic and ionotropic-sensing receptors [153-155]. Interestingly, astrocytes display $\mathrm{Ca}^{2+}$ transients that mirror neuronal activity [156-160]. In Drosophila, astrocyte $\mathrm{Ca}^{2+}$ signaling in the ventral nerve cord occurs in parallel with motor waves [161]. Similarly, co-imaging of $\mathrm{Ca}^{2+}$ transients in astrocytes and neurons following mouse whisker stimulation demonstrated that neuronal and glial calcium waves operate in synchrony during sensory tasks [162, 163]. Voluntary limb movements have also been shown to cause $\mathrm{Ca}^{2+}$ elevations of motor cortex astrocytes in awake, moving mice, suggesting efferent activity is tightly coupled to astrocyte activation [164]. It remains unclear whether astrocytic $\mathrm{Ca}^{2+}$ waves originate within the gap junction-coupled astroglial network, or represent the product of the linear summation of neighboring neuronal activity [165-169]. Nevertheless, we now understand that activity-dependent calcium elevation in astrocytes can induce release of small molecules including glutamate, ATP, and D-serine [170-173] in a calcium- and SNARE protein-dependent mechanism [174]. In turn, these "gliotransmitters" modify synaptic transmission and short-term plasticity (Fig. 3) [155, 161, 175-179]. For example, induction of calcium transients within astrocytes by direct manipulation or via inositol tris-phosphate-dependent signaling has been shown to depress or enhance synaptic transmission [154, 175, 180]. Recently, Ma et al. (2016) demonstrated that a Drosophila TRPA1 calcium channel (Water witch) is expressed in astrocytes and facilitates the accumulation of calcium in response to local neuronal activity. Astrocytic calcium can in turn modulate downstream dopaminergic neuron activity and locomotor behavior in vivo [161]. Indeed, it is now apparent that astrocytes are essential for rhythmic locomotor behaviors [93, 181-183]. In mouse, the sensory TRPA1 $\mathrm{Ca}^{2+}$ channel similarly maintains basal astrocytic calcium levels to facilitate constitutive D-serine release at the synapse. Loss of TRPA1 impairs NMDA-dependent LTP at Schaffer collateral to CA1 pyramidal neuron synapses, demonstrating that fine astrocytic processes tune synaptic plasticity in an activity-dependent manner
[184]. There is mounting evidence that astrocyte calcium signaling arises to modulate sensory-evoked neuronal activity. Well documented examples include somatosensory stimulations that trigger $\mathrm{Ca}^{2+}$ elevations in astrocytes which amplify stimulus-evoked cortical plasticity via noradrenaline and acetylcholine [185-188]. More recently, Lines et al. (2020) correlated the modulation of somatosensory afferents to astrocyte $\mathrm{Ca}^{2+}$ waves, and showed that astrocyte activation dampens sensory-evoked neuronal activity in S1 (primary somatosensory cortex) [160]; thus, placing bidirectional astrocyte-neuron communication at the center of sensory information processing in the mammalian cortex. This opens an exciting line of future work, where astrocytic activation could be manipulated to modulate neuronal activity during critical periods of circuit development and disease.

Finally, astrocyte networks may contribute to circuit plasticity during memory allocation and goal-directed behaviors. Ectopic activation of astrocytes is sufficient to induce de novo NMDA-dependent LTP in CA3-CA1 pyramidal neurons $[189,190]$. Interestingly, the authors also found that while direct neuronal activation impaired memory formation, delayed activation through astrocytes strongly enhanced memory allocation [190], suggesting that indirect signaling through astrocytes may be necessary to gate LTP. Indeed, a recent report suggests that gliotransmission by astrocytes recruits metabotropic glutamate receptors to the presynaptic terminal during spike timing-dependent plasticity, a process that shifts developing hippocampal synapses from long term depression (LTD) to LTP [191, 192] (Fig. 3). Extensive work in mouse models have also defined astrocytes as key regulators of inhibition. As aforementioned, astrocyte-derived NRCAM influences inhibitory synapse development and function in the developing visual cortex. Similarly, astrocytic activation in the limbic system can drive depression of excitatory synapses and enhancement of inhibitory synapses in the central amygdala [179]. In the developing somatosensory cortex, astrocytic signaling mediates spike-timing-dependent LTD [192, 193]; and in the developing prefrontal cortex, astrocytic $\mathrm{GABA}_{\mathrm{B}}$ receptors monitor local concentrations of GABA and in turn, regulate low gamma oscillations (see more below) and goal-directed behaviors [194]. Thus, bidirectional signaling between neurons and astrocytes ensures proper E/I balance in multiple brain regions to shapes the flow of information through neural circuits and facilitate neuronal plasticity that is essential for learning, memory, and goal-directed behaviors.

\section{Astrocytes and circuit pattern generation}

It is evident that astrocytes tune synaptic and circuit architecture during sensory-dependent plasticity. Yet, 


\section{Astrocytes regulate circuit function}

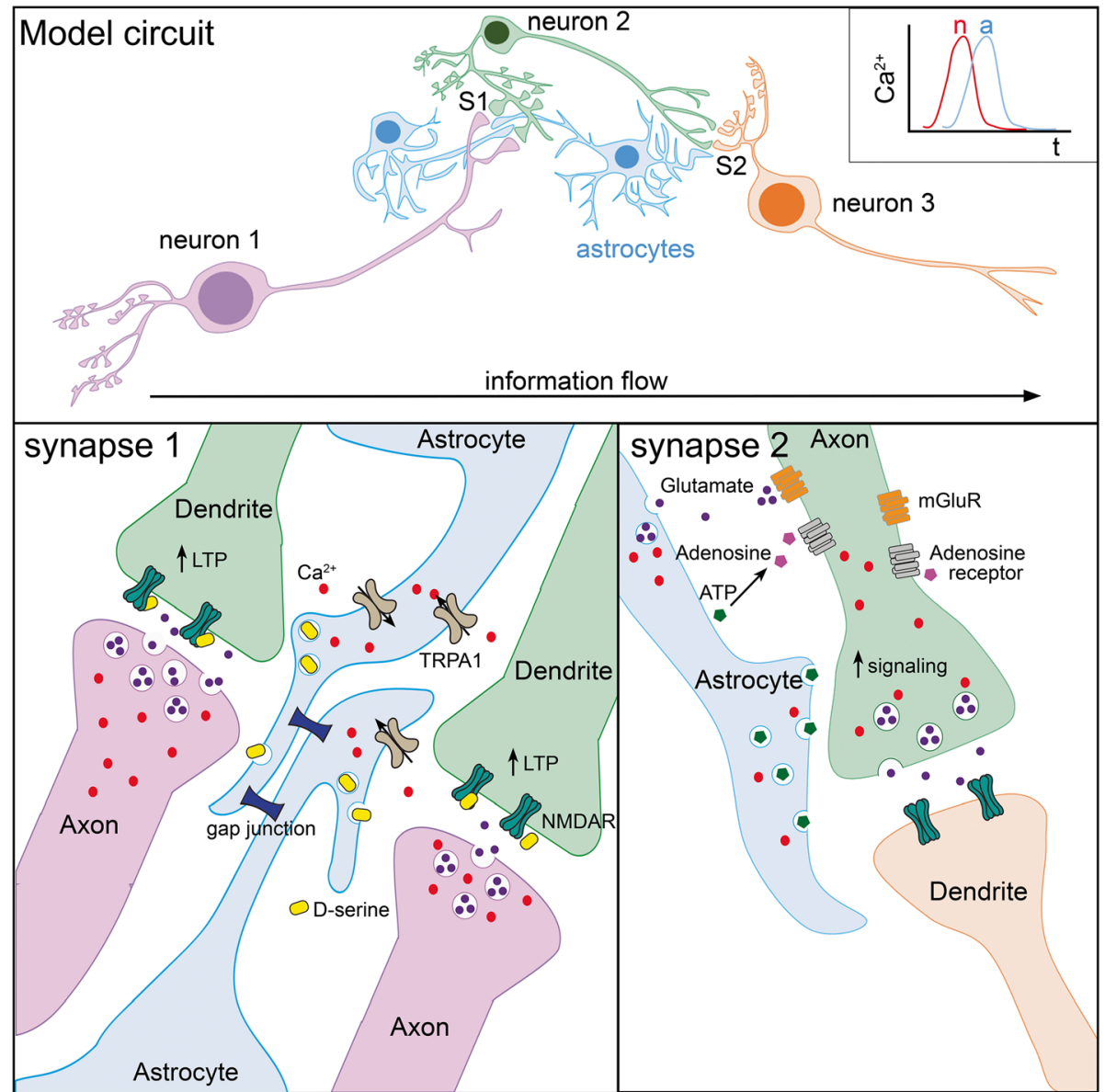

Fig. 3 Select mechanisms for astrocyte-modulated neuronal signaling.Top: Simple model circuit showing three linearly connected neurons (n) and associated astrocytes (a). at two synaptic (S) connections. Synapse 1: Influx of calcium into gap junction-coupled astrocytes via TRPA1 channels occurs in response to local neuronal activity. Elevation of astrocytic calcium causes astrocyte activation and release of gliotransmitters including D-serine, which induces NMDAR-dependent LTP. Synapse 2: Elevation of astrocytic calcium can also drive release of the gliotransmitters ATP and glutamate, which can stimulate pre-synaptic adenosine and metabotrophic glutamate (mGluR) receptors, respectively, to promote signaling of downstream neurons and drive the flow of information through the circuit

plasticity also occurs even during "idle" periods with little environmental input [195-197]. Since the discovery of electroencephalography [198], scientists have identified several rhythmic voltage fluctuations in the brain, from individual neurons to whole neuronal networks [199]. These oscillations emerge in all brain regions, and their patterns underlie the basis for internal day/night cycles, sensory representation, and short term memory [200, 201]. Astrocytes are capable of modulating neuronal rhythms by mediating ion homeostasis at the synapse [194, 202-206]. Interestingly, astrocyte-dependent ion homeostasis seems to be critical for oscillatory behaviors such as sleep $[207,208]$. Indeed, a suite of papers describing the role of astrocytes in sleep in fly and mouse were published in the last six months alone. In brief, astrocytes exhibit calcium waves that follow natural circadian rhythms- they are highest during wake phases and lowest during sleep [207, 209]. Interestingly, astrocytes accumulate high levels of calcium during wake cycles in order to encode sleep need [209-211], similar to astrocytic calcium encoding futility-induced passivity in zebrafish [178]; enhancing astrocytic calcium caused perpetual sleep in Drosophila [210] and reducing astrocytic calcium is necessary for slow-wave sleep in mouse [207]. Finally, this transition in behavioral state is dependent on the local concentration of neurotransmitters (dopamine, serotonin, and endocannabinoids) sensed by astrocytic receptors [212, 213]. It will be interesting to test whether high levels of neuronal activity during the day also drive sleep recovery (e.g. napping) in an astrocyte-dependent manner. Additionally, as sleeping behaviors can change dramatically over the course of 
organismal development (e.g. neonate versus adult humans) or with the seasons (e.g. torpor), it will be important to determine the degree to which astrocytes contribute to sleeping behaviors outside of the standard diurnal clock. Thus, astrocytes coordinate both developmental and homeostatic circuit activity from the scale of individual synapses to circuits.

\section{Concluding remarks}

Synaptic plasticity ensures the correct assembly and tuning of millions of synapses during nervous system development [82, 86]. From their perisynaptic location, astroglia have been shown to organize pre- and postsynaptic elements that modify Hebbian mechanisms of plasticity [27, 107, 190]. Moreover, astrocytes are also capable of instructing homeostatic plasticity both at the synapse and more broadly within neurons and circuits to counterbalance sustained periods of augmented activity [42, 93, 145]. Astrocytes even contribute to computation within neural networks to drive circuit and animal behavior [161, 178, 214]. Excitingly, a new study found that neuronal LTP can induce changes in astrocyte perisynaptic coverage to facilitate extended crosstalk between neighboring synapses [183]. Thus, a closer examination of how neurons and astrocytes bidirectionally interact and communicate during developmental circuit plasticity is warranted. The advent of genetic tools for visualization of astrocyte dynamics in zebrafish should provide a rich avenue for such exploration $[32,178]$.

Additionally, although calcium signaling in astrocyte perisynaptic processes often occurs in parallel with neuronal activity [162, 163, 167, 169], global calcium levels can act independently $[166,186]$. There is recent evidence suggesting that astrocyte networks modulate autonomic control of heart rate, such that astrocyte Cx43mediated release of ATP presumably regulates excitatory circuits in the brainstem[215]. Given the importance of local astrocytic signaling to circuit function, unraveling the importance of astrocyte-network signaling across broad brain regions is a necessary future line of research.

Finally, the rapid evolution of sequencing techniques has made the term "astrocyte" an umbrella-like category for a group of highly heterogeneous cells $[13,184,185$, 216]. Though there is some in vivo evidence that astrocytes can become locally specialized to provide circuitspecific support [13], this remains an open area ripe for future investigation. Future efforts should be directed at understanding how astrocytes acquire these unique expression profiles, and how this specialization guides their function within individual neurons and circuits. These types of experiments will require the development of intersectional tools that enable manipulation of specific subpopulations of astrocytes within the intact nervous system. Though challenging, the availability of single cell RNA sequencing datasets will undoubtedly speed up identification of region-specific markers that could be used for development of tools to test how functionally diverse astrocyte populations are in vivo, and how this diversity ensures proper neural circuit assembly and function.

\section{Abbreviations \\ AMPAR: a-amino-3-hydroxy-5-methyl-4-isoxazolepropionic receptors; APP: Amyloid precursor protein; ATP: Adenosine triphosphate; \\ Chrd11: Chordin like-1; CNS: Central nervous system; CSPG: Chondroitin sulfate proteoglycan; Cx: Connexin; E/l balance: Excitation to inhibition balance; GABA: Gamma aminobutyric acid; GJ: Gap junction; LTD: Long term depression; LTP: Long term potentiation; NMDAR: N-methyl-D-aspartate receptors; NRCAM: Neuronal cell adhesion molecule; RGC: Retinal ganglion cell; ODP: Ocular dominance plasticity; PNN: Perineuronal net; SPAR C: Secreted Protein Acidic and Rich in Cysteine; TRPA1: Transient Receptor Potential Cation Channel Subfamily A Member 1; TX: Tetrodotoxin}

\section{Acknowledgements}

not applicable.

\section{Author contributions}

NPC and SDA co-wrote the manuscript, with feedback provided by CQD. All authors commented and approved of the manuscript.

\section{Funding}

Funding was provided by HHMI (CQD), R01 HD27056 (CQD), and NIH F32NS098690 (SDA). SDA is a Milton Safenowitz Postdoctoral fellow of the ALSA.

\section{Availability of data and materials}

Data sharing is not applicable to this article as no datasets were generated or analysed during the current study.

Ethics approval and consent to participate

Not applicable.

\section{Consent for publication}

Not applicable.

\section{Competing interests}

The authors declare no competing financial interests.

\section{Author details}

${ }^{1}$ Institute of Neuroscience, Howard Hughes Medical Institute, University of Oregon, Eugene, OR, USA. ${ }^{2}$ Kennedy Center, Department of Pediatrics, The University of Chicago, Chicago, IL, USA.

Received: 25 September 2020 Accepted: 26 December 2020 Published online: 07 January 2021

\section{References}

1. Dubois B, Hampel H, Feldman HH, Scheltens P, Aisen P, Andrieu S, et al. Preclinical Alzheimer's disease: Definition, natural history, and diagnostic criteria. Alzheimers Dement J Alzheimers Assoc. 2016;12:292-323.

2. Burk K, Pasterkamp RJ. Disrupted neuronal trafficking in amyotrophic lateral sclerosis. Acta Neuropathol (Berl). 2019;137:859-77.

3. Faraone SV, Larsson H. Genetics of attention deficit hyperactivity disorder. Mol Psychiatry. 2019;24:562-75.

4. Eissa N, Al-Houqani M, Sadeq A, Ojha SK, Sasse A, Sadek B. Current Enlightenment About Etiology and Pharmacological Treatment of Autism Spectrum Disorder. Front Neurosci. 2018;12.

5. Keller R, Basta R, Salerno L, Elia M. Autism, epilepsy, and synaptopathies: a not rare association. Neurol Sci. 2017:38:1353-61.

6. Boyle CA, Boulet S, Schieve LA, Cohen RA, Blumberg SJ, Yeargin-Allsopp M, et al. Trends in the prevalence of developmental disabilities in US children, 1997-2008. Pediatrics. 2011;127:1034-42. 
7. Jäkel S, Dimou L. Glial Cells and Their Function in the Adult Brain: A Journey through the History of Their Ablation. Front Cell Neurosci. Frontiers; 2017;11.

8. Allen NJ, Eroglu C. Cell biology of astrocyte-synapse interactions. Neuron. 2017;96:697-708

9. Ventura R, Harris KM. Three-Dimensional Relationships between Hippocampal Synapses and Astrocytes. J Neurosci Society for Neuroscience. 1999:19:6897-906.

10. Lenhossek MV. Zur Kenntnis der Neuroglia des menschlichen Rückenmarkes. Verh Anat Ges. 1891;193-221.

11. Chaboub LS, Deneen B. Developmental origins of astrocyte heterogeneity: the final frontier of CNS development. Dev Neurosci. 2012;34:379-88.

12. Tsai H-H, Li H, Fuentealba LC, Molofsky AV, Taveira-Marques R, Zhuang H, et al. Regional astrocyte allocation regulates CNS synaptogenesis and repair. Science. 2012;337:358-62.

13. Molofsky AV, Kelley KW, Tsai H-H, Redmond SA, Chang SM, Madireddy L, et al. Astrocyte-encoded positional cues maintain sensorimotor circuit integrity. Nature. 2014;509:189-94

14. Zhang Y, Sloan SA, Clarke LE, Caneda C, Plaza CA, Blumenthal PD, et al. Purification and Characterization of Progenitor and Mature Human Astrocytes Reveals Transcriptional and Functional Differences with Mouse. Neuron. 2016;89:37-53.

15. Miller SJ. Astrocyte Heterogeneity in the Adult Central Nervous System. Frontiers: Front Cell Neurosci; 2018. p. 12.

16. Fan $X, F u Y$, Zhou $X$, Sun $L$, Yang $M$, Wang $M$, et al. Single-cell transcriptome analysis reveals cell lineage specification in temporal-spatial patterns in human cortical development. Sci Adv. American Association for the Advancement of Science; 2020;6:eaaz2978.

17. Sagner A, Briscoe J. Establishing neuronal diversity in the spinal cord: a time and a place. Dev Camb Engl. 2019;146.

18. Bayraktar OA, Bartels T, Holmqvist S, Kleshchevnikov V, Martirosyan A, Polioudakis D, et al. Astrocyte layers in the mammalian cerebral cortex revealed by a single-cell in situ transcriptomic map. Nat Neurosci Nature Publishing Group. 2020;23:500-9.

19. Freeman MR, Rowitch DH. Evolving Concepts of Gliogenesis: A Look Way Back and Ahead to the Next 25 Years. Neuron. 2013:80:613-23.

20. Abbink MR, van Deijk AF, Heine VM, Verheijen MH, Korosi A. The involvement of astrocytes in early-life adversity induced programming of the brain. Glia. 2019;67:1637-53.

21. Allen NJ, Bennett ML, Foo LC, Wang GX, Chakraborty C, Smith SJ, et al. Astrocyte glypicans 4 and 6 promote formation of excitatory synapses via GluA1 AMPA receptors. Nature. Nature Publishing Group. 2012:486:410-4.

22. Baldwin KT, Eroglu C. Molecular mechanisms of astrocyte-induced synaptogenesis. Curr Opin Neurobiol. 2017;45:113-20.

23. Barker AJ, Koch SM, Reed J, Barres BA, Ullian EM. Developmental control of synaptic receptivity. J Neurosci Off J Soc Neurosci. 2008;28:8150-60.

24. Buosi AS, Matias I, Araujo APB, Batista C, Gomes FCA. Heterogeneity in Synaptogenic Profile of Astrocytes from Different Brain Regions. Mol Neurobiol. 2018:55:751-62.

25. Christopherson KS, Ullian EM, Stokes CCA, Mullowney CE, Hell JW, Agah A, et al. Thrombospondins Are Astrocyte-Secreted Proteins that Promote CNS Synaptogenesis. Cell Elsevier. 2005;120:421-33.

26. Kucukdereli $\mathrm{H}$, Allen NJ, Lee AT, Feng A, Ozlu MI, Conatser LM, et al. Control of excitatory CNS synaptogenesis by astrocyte-secreted proteins Hevin and SPARC. Proc Natl Acad Sci U S A. 2011:108:E440-9.

27. Singh SK, Stogsdill JA, Pulimood NS, Dingsdale H, Kim YH, Pilaz L-J, et al. Astrocytes Assemble Thalamocortical Synapses by Bridging NRX1a and NL1 via Hevin. Cell Elsevier. 2016;164:183-96.

28. Ullian EM. Control of Synapse Number by Glia. Science. 2001;291:657-61.

29. Bayraktar OA, Fuentealba LC, Alvarez-Buylla A, Rowitch DH. Astrocyte Development and Heterogeneity. Cold Spring Harb Perspect Biol. Cold Spring Harbor Laboratory Press; 2015;7.

30. Yoon $H$, Walters $G$, Paulsen AR, Scarisbrick IA. Astrocyte heterogeneity across the brain and spinal cord occurs developmentally, in adulthood and in response to demyelination. PLOS ONE Public Library of Science. 2017;12:e0180697.

31. Freeman MR. Drosophila Central Nervous System Glia. Cold Spring Harb Perspect Biol. 2015;7.

32. Chen J, Poskanzer KE, Freeman MR, Monk KR. Live-imaging of astrocyte morphogenesis and function in zebrafish neural circuits. Nat Neurosci. Nature Publishing Group; 2020;1-10.

33. deAzevedo LC, Fallet C, Moura-Neto V, Daumas-Duport C, Hedin-Pereira C, Lent R. Cortical radial glial cells in human fetuses: Depth-correlated transformation into astrocytes. J Neurobiol. 2003;55:288-98.
34. Kanski R, van Strien ME, van Tijn P, Hol EM. A star is born: new insights into the mechanism of astrogenesis. Cell Mol Life Sci CMLS. 2014;71:433-47.

35. Frisén J. Neurogenesis and Gliogenesis in Nervous System Plasticity and Repair. Annu Rev Cell Dev Biol. 2016;32:127-41.

36. Oberheim NA, Wang X, Goldman S, Nedergaard M. Astrocytic complexity distinguishes the human brain. Trends Neurosci. 2006:29:547-53.

37. de Majo M, Koontz M, Rowitch D, Ullian EM. An update on human astrocytes and their role in development and disease. Glia. 2020;68:685-704.

38. Nedergaard M, Ransom B, Goldman SA. New roles for astrocytes: redefining the functional architecture of the brain. Trends Neurosci. 2003;26:523-30.

39. Oberheim NA, Takano T, Han X, He W, Lin JHC, Wang F, et al. Uniquely hominid features of adult human astrocytes. J Neurosci Off J Soc Neurosci. 2009:29:3276-87.

40. Cassé F, Richetin K, Toni N. Astrocytes' Contribution to Adult Neurogenesis in Physiology and Alzheimer's Disease. Front Cell Neurosci. 2018;12.

41. Liddelow SA, Barres BA. Reactive Astrocytes: Production, Function, and Therapeutic Potential. Immunity. 2017:46:957-67.

42. Blanco-Suarez E, Liu T-F, Kopelevich A, Allen NJ. Astrocyte-secreted chordin like 1 drives synapse maturation and limits plasticity by increasing synaptic GluA2 AMPA receptors. Neuron. 2018;100:1116-32.e13.

43. Chung W-S, Clarke LE, Wang GX, Stafford BK, Sher A, Chakraborty C, et al. Astrocytes mediate synapse elimination through MEGF10 and MERTK pathways. Nature. 2013;504:394-400.

44. Tasdemir-Yilmaz OE, Freeman MR. Astrocytes engage unique molecular programs to engulf pruned neuronal debris from distinct subsets of neurons. Genes Dev. 2014;28:20-33.

45. Meyer-Franke A, Kaplan MR, Pfrieger FW, Barres BA. Characterization of the signaling interactions that promote the survival and growth of developing retinal ganglion cells in culture. Neuron. 1995;15:805-19.

46. Pfrieger FW, Barres BA. Synaptic efficacy enhanced by glial cells in vitro. Science. 1997;277:1684-7.

47. Nägler K, Mauch DH, Pfrieger FW. Glia-derived signals induce synapse formation in neurones of the rat central nervous system. J Physiol. 2001;533: $665-79$

48. Sloan SA, Darmanis S, Huber N, Khan TA, Birey F, Caneda C, et al. Human Astrocyte Maturation Captured in 3D Cerebral Cortical Spheroids Derived from Pluripotent Stem Cells. Neuron. 2017;95:779-90.e6.

49. Colón-Ramos DA, Margeta MA, Shen K. Glia Promote Local Synaptogenesis Through UNC-6 (Netrin) Signaling in C. elegans. Science. American Association for the Advancement of Science; 2007;318:103-6.

50. Doherty J, Logan MA, Taşdemir ÖE, Freeman MR. Ensheathing Glia Function as Phagocytes in the Adult Drosophila Brain. J Neurosci Society for Neuroscience. 2009;29:4768-81.

51. Shigetomi E, Kracun S, Sofroniew MV, Khakh BS. A genetically targeted optical sensor to monitor calcium signals in astrocyte processes. Nat Neurosci Nature Publishing Group. 2010;13:759-66.

52. Tien A-C, Tsai H-H, Molofsky AV, McMahon M, Foo LC, Kaul A, et al. Regulated temporal-spatial astrocyte precursor cell proliferation involves BRAF signalling in mammalian spinal cord. 139. Development: Oxford University Press for The Company of Biologists Limited; 2012. pp. 2477-87.

53. Srinivasan R, Lu T-Y, Chai H, Xu J, Huang BS, Golshani P, et al. New Transgenic Mouse Lines for Selectively Targeting Astrocytes and Studying Calcium Signals in Astrocyte Processes In Situ and In Vivo. Neuron. 2016:92:1181-95.

54. Shao Z, Watanabe S, Christensen R, Jorgensen EM, Colón-Ramos DA. Synapse Location during Growth Depends on Glia Location. Cell Elsevier. 2013;154:337-50.

55. Singhvi A, Shaham S. Glia-Neuron Interactions in Caenorhabditis elegans. Annu Rev Neurosci. 2019:42:149-68.

56. Muthukumar AK, Stork T, Freeman MR. Activity-dependent regulation of astrocyte GAT levels during synaptogenesis. Nat Neurosci Nature Publishing Group. 2014;17:1340-50

57. Yildirim K, Petri J, Kottmeier R, Klämbt C. Drosophila glia: Few cell types and many conserved functions. Glia. 2019;67:5-26.

58. Müller CM, Best J. Ocular dominance plasticity in adult cat visual cortex after transplantation of cultured astrocytes. Nature Nature Publishing Group. 1989:342:427-30.

59. López-Murcia FJ, Terni B, Llobet A. SPARC triggers a cell-autonomous program of synapse elimination. Proc Natl Acad Sci U S A. 2015:112:13366-71.

60. Hartley RS, Margulis M, Fishman PS, Lee VM, Tang CM. Functional synapses are formed between human NTera2 (NT2N, hNT) neurons grown on astrocytes. J Comp Neurol. 1999;407:1-10. 
61. Johnson MA, Weick JP, Pearce RA, Zhang S-C. Functional Neural Development from Human Embryonic Stem Cells: Accelerated Synaptic Activity via Astrocyte Coculture. J Neurosci Society for Neuroscience. 2007; 27:3069-77.

62. Chung W-S, Welsh CA, Barres BA, Stevens B. Do Glia Drive Synaptic and Cognitive Impairment in Disease? Nat Neurosci. 2015:18:1539-45.

63. Allen NJ. Astrocyte regulation of synaptic behavior. Annu Rev Cell Dev Biol. 2014;30:439-63.

64. Wallingford J, Scott AL, Rodrigues K, Doering LC. Altered Developmental Expression of the Astrocyte-Secreted Factors Hevin and SPARC in the Fragile X Mouse Model. Front Mol Neurosci. Frontiers; 2017;10.

65. Liu X, Ying G, Wang W, Dong J, Wang Y, Ni Z, et al. Entorhinal deafferentation induces upregulation of SPARC in the mouse hippocampus. Mol Brain Res. 2005;141:58-65.

66. Lively S, Brown IR. Analysis of the extracellular matrix protein SC1 during reactive gliosis in the rat lithium-pilocarpine seizure model. Brain Res. 2007; 1163:1-9.

67. Lively S, Moxon-Emre I, Schlichter LC. SC1/hevin and reactive gliosis after transient ischemic stroke in young and aged rats. J Neuropathol Exp Neurol. 2011;70:913-29

68. Cahoy JD, Emery B, Kaushal A, Foo LC, Zamanian JL, Christopherson KS, et al. A Transcriptome Database for Astrocytes, Neurons, and Oligodendrocytes: A New Resource for Understanding Brain Development and Function. J Neurosci Society for Neuroscience. 2008;28:264-78.

69. Zhang Y, Chen K, Sloan SA, Bennett ML, Scholze AR, O'Keeffe S, et al. An RNA-sequencing transcriptome and splicing database of glia, neurons, and vascular cells of the cerebral cortex. J Neurosci Off J Soc Neurosci. 2014;34 11929-47.

70. Risher WC, Patel S, Kim IH, Uezu A, Bhagat S, Wilton DK, et al. Astrocytes refine cortical connectivity at dendritic spines. eLife. 2014;3.

71. Takano T, Wallace JT, Baldwin KT, Purkey AM, Uezu A, Courtland JL, et al. Chemico-genetic discovery of astrocytic control of inhibition in vivo. Nature. 2020;588:296-302.

72. Huttenlocher PR, Dabholkar AS. Regional differences in synaptogenesis in human cerebral cortex. J Comp Neurol. 1997;387:167-78.

73. Ziegenfuss JS, Biswas R, Avery MA, Hong K, Sheehan AE, Yeung Y-G, et al. Draper-dependent glial phagocytic activity is mediated by Src and Syk family kinase signalling. Nature Nature Publishing Group. 2008;453:935-9.

74. Hakim Y, Yaniv SP, Schuldiner O. Astrocytes Play a Key Role in Drosophila Mushroom Body Axon Pruning. PLoS ONE. 2014;9.

75. Roberts TF, Tschida KA, Klein ME, Mooney R. Rapid spine stabilization and synaptic enhancement at the onset of behavioural learning. Nature Nature Publishing Group. 2010;463:948-52.

76. Neniskyte U, Gross CT. Errant gardeners: glial-cell-dependent synaptic pruning and neurodevelopmental disorders. Nat Rev Neurosci Nature Publishing Group. 2017;18:658-70

77. Damisah EC, Hill RA, Rai A, Chen F, Rothlin CV, Ghosh S, et al. Astrocytes and microglia play orchestrated roles and respect phagocytic territories during neuronal corpse removal in vivo. Sci Adv. 2020;6:eaba3239.

78. Kessissoglou IA, Langui D, Hasan A, Maral M, Dutta SB, Hiesinger PR, et al. The Drosophila amyloid precursor protein homologue mediates neuronal survival and neuroglial interactions. PLoS Biol. 2020;18:e3000703.

79. Citri A, Malenka RC. Synaptic Plasticity: Multiple Forms, Functions, and Mechanisms. Neuropsychopharmacology Nature Publishing Group. 2008;33: 18-41.

80. Maffei A, Turrigiano G. Chapter 12 The age of plasticity: Developmental regulation of synaptic plasticity in neocortical microcircuits. In: Sossin WS, Lacaille J-C, Castellucci VF, Belleville S, editors. Prog Brain Res. Elsevier; 2008. p. 211-23.

81. Kolb B, Gibb R. Brain Plasticity and Behaviour in the Developing Brain. J Can Acad Child Adolesc Psychiatry. 2011;20:265-76

82. Hensch TK. Critical Period Regulation. Annu Rev Neurosci. 2004;27:549-79.

83. Miller KD, MacKay DJC. The Role of Constraints in Hebbian Learning. Neural Comput MIT Press. 1994;6:100-26.

84. Lazar A, Pipa G, Triesch J. SORN: a self-organizing recurrent neural network. Front Comput Neurosci. Frontiers; 2009;3.

85. Hebb DO. The Organization of Behavior: A Neuropsychological Theory. Wiley; 1949

86. Keck T, Toyoizumi T, Chen L, Doiron B, Feldman DE, Fox K, et al. Integrating Hebbian and homeostatic plasticity: the current state of the field and future research directions. Philos Trans R Soc B Biol Sci. 2017;372.
87. Nicoll RA. A Brief History of Long-Term Potentiation. Neuron. 2017;93:281-

88. Fox K, Stryker M. Integrating Hebbian and homeostatic plasticity: introduction. Philos Trans R Soc B Biol Sci. 2017:372.

89. Desai NS, Cudmore RH, Nelson SB, Turrigiano GG. Critical periods for experience-dependent synaptic scaling in visual cortex. Nat Neurosci Nature Publishing Group. 2002;5:783-9.

90. Evers JF, Mauss A, Bate M, Landgraf M, Tripodi M. Structural Homeostasis: Compensatory Adjustments of Dendritic Arbor Geometry in Response to Variations of Synaptic Input. PLOS Biol. 2008;6:e260.

91. Roy B, Singh AP, Shetty C, Chaudhary V, North A, Landgraf M, et al. Metamorphosis of an identified serotonergic neuron in the Drosophila olfactory system. Neural Develop. 2007:2:20.

92. Yuan Q, Xiang Y, Yan Z, Han C, Jan LY, Jan YN. Light-induced structural and functional plasticity in Drosophila larval visual system. Science. 2011;333: 1458-62.

93. Ackerman SD, Perez-Catalan NA, Freeman MR, Doe CQ. Astrocytes close a critical period of motor circuit plasticity. bioRxiv. 2020;2020.05.15.098608.

94. Pannasch U, Vargová L, Reingruber J, Ezan P, Holcman D, Giaume C, et al. Astroglial networks scale synaptic activity and plasticity. Proc Natl Acad Sci National Academy of Sciences. 2011:108:8467-72.

95. Mederos S, González-Arias C, Perea G. Astrocyte-Neuron Networks: A Multilane Highway of Signaling for Homeostatic Brain Function. Frontiers: Front Synaptic Neurosci; 2018. p. 10.

96. Hansen KB, Yi F, Perszyk RE, Furukawa H, Wollmuth LP, Gibb AJ, et al. Structure, function, and allosteric modulation of NMDA receptors. J Gen Physiol The Rockefeller University Press. 2018;150:1081-105.

97. Bliss TVP, Lømo T. Long-lasting potentiation of synaptic transmission in the dentate area of the anaesthetized rabbit following stimulation of the perforant path. J Physiol. 1973;232:331-56.

98. Groc L, Heine M, Cognet L, Brickley K, Stephenson FA, Lounis B, et al. Differential activity-dependent regulation of the lateral mobilities of AMPA and NMDA receptors. Nat Neurosci Nature Publishing Group. 2004;7:695-6.

99. Heine $M$, Groc L, Frischknecht R, Béïque J-C, Lounis B, Rumbaugh $G$, et al. Surface mobility of postsynaptic AMPARs tunes synaptic transmission. Science. 2008:320:201-5.

100. Wiesel TN, Hubel DH. Single-cell responses in striate cortex of kittens deprived of vision in one eye. J Neurophysiol American Physiological Society. 1963;26:1003-17.

101. Levelt CN, Hübener M. Critical-Period Plasticity in the Visual Cortex. Annu Rev Neurosci Annual Reviews. 2012;35:309-30.

102. Spiegel DP, Baldwin AS, Hess RF. Ocular dominance plasticity: inhibitory interactions and contrast equivalence. Sci Rep Nature Publishing Group. 2017:7:39913.

103. Bear M, Kleinschmidt A, Gu Q, Singer W. Disruption of experiencedependent synaptic modifications in striate cortex by infusion of an NMDA receptor antagonist. J Neurosci. 1990;10:909-25.

104. Roberts EB, Meredith MA, Ramoa AS. Suppression of NMDA Receptor Function Using Antisense DNA Blocks Ocular Dominance Plasticity While Preserving Visual Responses. J Neurophysiol American Physiological Society. 1998:80:1021-32.

105. Sawtell NB, Frenkel MY, Philpot BD, Nakazawa K, Tonegawa S, Bear MF. NMDA receptor-dependent ocular dominance plasticity in adult visual cortex. Neuron. 2003;38:977-85.

106. Stogsdill JA, Eroglu C. The interplay between neurons and glia in synapse development and plasticity. Curr Opin Neurobiol. 2017;42:1-8.

107. Jones EV, Bernardinelli Y, Tse YC, Chierzi S, Wong TP, Murai KK. Astrocytes control glutamate receptor levels at developing synapses through SPARCbeta-integrin interactions. J Neurosci Off J Soc Neurosci. 2011;31:4154-65.

108. Houades V, Koulakoff A, Ezan P, Seif I, Giaume C. Gap Junction-Mediated Astrocytic Networks in the Mouse Barrel Cortex. J Neurosci. 2008;28:520717.

109. Giaume C, Koulakoff A, Roux L, Holcman D, Rouach N. Astroglial networks: a step further in neuroglial and gliovascular interactions. Nat Rev Neurosci Nature Publishing Group. 2010;11:87-99.

110. Dallérac G, Zapata J, Rouach N. Versatile control of synaptic circuits by astrocytes: where, when and how? Nat Rev Neurosci. Nature Publishing Group. 2018;19:729-43.

111. Rouach N, Koulakoff A, Abudara V, Willecke K, Giaume C. Astroglial Metabolic Networks Sustain Hippocampal Synaptic Transmission. Science. American Association for the Advancement of Science; 2008;322:1551-5. 
112. Verkhratsky A, Zorec R, Rodriguez-Arellano JJ, Parpura V. Neuroglia in Ageing. Adv Exp Med Biol. 2019;1175:181-97.

113. Nagy JI, Dudek FE, Rash JE. Update on connexins and gap junctions in neurons and glia in the mammalian nervous system. Brain Res Rev. 2004;47: $191-215$.

114. Giaume C, Liu X. From a glial syncytium to a more restricted and specific glial networking. J Physiol-Paris. 2012;106:34-9.

115. Murphy-Royal C, Johnston AD, Boyce AKJ, Diaz-Castro B, Institoris $A$ Peringod G, et al. Author Correction: Stress gates an astrocytic energy reservoir to impair synaptic plasticity. Nat Commun Nature Publishing Group. 2020;11:3064

116. Pannasch U, Freche D, Dallérac G, Ghézali G, Escartin C, Ezan P, et al. Connexin 30 sets synaptic strength by controlling astroglial synapse invasion. Nat Neurosci. 2014;17:549-58.

117. Lutz SE, Zhao Y, Gulinello M, Lee SC, Raine CS, Brosnan CF. Deletion of Astrocyte Connexins 43 and 30 Leads to a Dysmyelinating Phenotype and Hippocampal CA1 Vacuolation. J Neurosci. 2009;29:7743-52.

118. Dzyubenko E, Gottschling C, Faissner A. Neuron-Glia Interactions in Neural Plasticity: Contributions of Neural Extracellular Matrix and Perineuronal Nets, Neural Plast. 2016;2016.

119. Deepa SS, Carulli D, Galtrey C, Rhodes K, Fukuda J, Mikami T, et al. Composition of Perineuronal Net Extracellular Matrix in Rat Brain: A Different Disaccharide Composition For The Net-Associated Proteoglycans. J Biol Chem. 2006;281:17789-800.

120. Fawcett JW, Oohashi T, Pizzorusso T. The roles of perineuronal nets and the perinodal extracellular matrix in neuronal function. Nat Rev Neurosci Nature Publishing Group. 2019;20:451-65.

121. Frischknecht $R$, Heine $M$, Perrais $D$, Seidenbecher $C l$, Choquet $D$, Gundelfinger ED. Brain extracellular matrix affects AMPA receptor lateral mobility and short-term synaptic plasticity. Nat Neurosci. 2009;12:897-904.

122. Carulli D, Broersen R, de Winter F, Muir EM, Mešković M, de Waal M, et al. Cerebellar plasticity and associative memories are controlled by perineuronal nets. Proc Natl Acad Sci U S A. 2020;117:6855-65.

123. McKeon RJ, Jurynec MJ, Buck CR. The chondroitin sulfate proteoglycans neurocan and phosphacan are expressed by reactive astrocytes in the chronic CNS glial scar. J Neurosci Off J Soc Neurosci. 1999:19:10778-88.

124. Smith GM, Strunz C. Growth factor and cytokine regulation of chondroitin sulfate proteoglycans by astrocytes. Glia. 2005;52:209-18.

125. Chan CCM, Wong AK, Liu J, Steeves JD, Tetzlaff W. ROCK inhibition with Y27632 activates astrocytes and increases their expression of neurite growth-inhibitory chondroitin sulfate proteoglycans. Glia. 2007;55:369-84.

126. Massey JM, Amps J, Viapiano MS, Matthews RT, Wagoner MR, Whitaker CM, et al. Increased chondroitin sulfate proteoglycan expression in denervated brainstem targets following spinal cord injury creates a barrier to axonal regeneration overcome by chondroitinase $A B C$ and neurotrophin-3. Exp Neurol. 2008;209:426-45.

127. Geissler M, Gottschling C, Aguado A, Rauch U, Wetzel CH, Hatt H, et al. Primary Hippocampal Neurons, Which Lack Four Crucial Extracellular Matrix Molecules, Display Abnormalities of Synaptic Structure and Function and Severe Deficits in Perineuronal Net Formation. J Neurosci. 2013;33:7742-55.

128. Moon LDF, Asher RA, Rhodes KE, Fawcett JW. Regeneration of CNS axons back to their target following treatment of adult rat brain with chondroitinase ABC. Nat Neurosci Nature Publishing Group. 2001:4:465-6.

129. Shields LBE, Zhang YP, Burke DA, Gray R, Shields CB. Benefit of Chondroitinase ABC on Sensory Axon Regeneration in a Laceration Model of Spinal Cord Injury in the Rat. Surg Neurol. 2008;69:568-77.

130. Keough MB, Rogers JA, Zhang P, Jensen SK, Stephenson EL, Chen T, et al. An inhibitor of chondroitin sulfate proteoglycan synthesis promotes central nervous system remyelination. Nat Commun Nature Publishing Group. 2016 7:11312.

131. Mahajan R. Chondroitinase ABC, Enzyme. A Potential Treatment Option for Spinal Cord Injury. Int J Appl Basic Med Res. 2018;8:203.

132. Turrigiano GG. The self-tuning neuron: synaptic scaling of excitatory synapses. Cell. 2008;135:422-35.

133. Axelsson J, Thesleff S. A study of supersensitivity in denervated mammalian skeletal muscle. J Physiol. 1959;147:178-93.

134. Bienenstock EL, Cooper LN, Munro PW. Theory for the development of neuron selectivity: orientation specificity and binocular interaction in visual cortex. J Neurosci Society for Neuroscience. 1982;2:32-48.

135. Oja E. Simplified neuron model as a principal component analyzer. J Math Biol. 1982;15:267-73.
136. Turrigiano G, Abbott LF, Marder E. Activity-dependent changes in the intrinsic properties of cultured neurons. Science. 1994;264:974-7.

137. Davis GW, DiAntonio A, Petersen SA, Goodman CS. Postsynaptic PKA Controls Quantal Size and Reveals a Retrograde Signal that Regulates Presynaptic Transmitter Release in Drosophila. Neuron. 1998;20:305-15.

138. Turrigiano GG, Leslie KR, Desai NS, Rutherford LC, Nelson SB. Activitydependent scaling of quantal amplitude in neocortical neurons. Nature. 1998;391:892-6.

139. Paradis S, Sweeney ST, Davis GW. Homeostatic Control of Presynaptic Release Is Triggered by Postsynaptic Membrane Depolarization. Neuron. 2001:30:737-49.

140. Hengen KB, Lambo ME, Van Hooser SD, Katz DB, Turrigiano GG. Firing rate homeostasis in visual cortex of freely behaving rodents. Neuron. 2013;80: 335-42.

141. Li J, Park E, Zhong L, Chen L. Homeostatic synaptic plasticity as a metaplasticity mechanism - a molecular and cellular perspective. Curr Opin Neurobiol. 2019;54:44-53.

142. Lee H-K, Kirkwood A. Mechanisms of Homeostatic Synaptic Plasticity in vivo. Front Cell Neurosci. Frontiers; 2019;13.

143. Hou Q, Zhang D, Jarzylo L, Huganir RL, Man H-Y. Homeostatic regulation of AMPA receptor expression at single hippocampal synapses. Proc Natl Acad Sci U S A. 2008;105:775-80.

144. Turrigiano GG, Nelson SB. Homeostatic plasticity in the developing nervous system. Nat Rev Neurosci. 2004;5:97-107.

145. Turrigiano GG. More than a sidekick: glia and homeostatic synaptic plasticity. Trends Mol Med. 2006;12:458-60.

146. Mendis DB, Malaval L, Brown IR. SPARC, an extracellular matrix glycoprotein containing the follistatin module, is expressed by astrocytes in synaptic enriched regions of the adult brain. Brain Res. 1995;676:69-79.

147. Eroglu C. The role of astrocyte-secreted matricellular proteins in central nervous system development and function. J Cell Commun Signal. 2009;3: 167-76.

148. Bailey CH, Kandel ER, Harris KM. Structural Components of Synaptic Plasticity and Memory Consolidation. Cold Spring Harb Perspect Biol. 2015;7.

149. Sheng C, Javed U, Gibbs M, Long C, Yin J, Qin B, et al. Experiencedependent structural plasticity targets dynamic filopodia in regulating dendrite maturation and synaptogenesis. Nat Commun. 2018;9:3362.

150. Kim SK, Hayashi H, Ishikawa T, Shibata K, Shigetomi E, Shinozaki $Y$, et al. Cortical astrocytes rewire somatosensory cortical circuits for peripheral neuropathic pain. J Clin Invest. 2016;126:1983-97.

151. Nys J, Scheyltjens I, Arckens L. Visual system plasticity in mammals: the story of monocular enucleation-induced vision loss. Front Syst Neurosci. 2015;9.

152. LeBlanc JJ, Fagiolini M. Autism: a "critical period". disorder? Neural Plast. 2011;2011:921680.

153. Porter JT, McCarthy KD. Hippocampal Astrocytes In Situ Respond to Glutamate Released from Synaptic Terminals. J Neurosci Society for Neuroscience. 1996;16:5073-81.

154. Pasti L, Volterra A, Pozzan T, Carmignoto G. Intracellular calcium oscillations in astrocytes: a highly plastic, bidirectional form of communication between neurons and astrocytes in situ. J Neurosci Off J Soc Neurosci. 1997;17:7817-30.

155. Perea G, Araque A. Properties of synaptically evoked astrocyte calcium signal reveal synaptic information processing by astrocytes. J Neurosci Off J Soc Neurosci. 2005:25:2192-203.

156. Cornell-Bell AH, Finkbeiner SM, Cooper MS, Smith SJ. Glutamate induces calcium waves in cultured astrocytes: long-range glial signaling. Science. 1990;247:470-3.

157. Dani JW, Chernjavsky A, Smith SJ. Neuronal activity triggers calcium waves in hippocampal astrocyte networks. Neuron. 1992;8:429-40.

158. Newman EA, Zahs KR. Calcium waves in retinal glial cells. Science. 1997;275:844-7.

159. Nimmerjahn A, Kirchhoff F, Kerr JND, Helmchen F. Sulforhodamine 101 as a specific marker of astroglia in the neocortex in vivo. Nat Methods. 2004;1:31-7.

160. Lines J, Martin ED, Kofuji P, Aguilar J, Araque A. Astrocytes modulate sensory-evoked neuronal network activity. Nat Commun. 2020;11:3689.

161. Ma Z, Stork T, Bergles DE, Freeman MR. Neuromodulators signal through astrocytes to alter neural circuit activity and behaviour. Nature. 2016;539:428-32.

162. Wang X, Takano T, Nedergaard M. Astrocytic Calcium Signaling: Mechanism and Implications for Functional Brain Imaging. Methods Mol Biol Clifton NJ. 2009:489:93-109.

163. Stobart JL, Ferrari KD, Barrett MJP, Glück C, Stobart MJ, Zuend M, et al. Cortical Circuit Activity Evokes Rapid Astrocyte Calcium Signals on a Similar Timescale to Neurons. Neuron. 2018;98:726-35.e4. 
164. Dombeck DA, Khabbaz AN, Collman F, Adelman TL, Tank DW. Imaging Large-Scale Neural Activity with Cellular Resolution in Awake, Mobile Mice. Neuron. 2007;56:43-57

165. Guerra-Gomes S, Sousa N, Pinto L, Oliveira JF. Functional Roles of Astrocyte Calcium Elevations: From Synapses to Behavior. Frontiers: Front Cell Neurosci; 2018. p. 11

166. Nett WJ, Oloff SH, McCarthy KD. Hippocampal Astrocytes In Situ Exhibit Calcium Oscillations That Occur Independent of Neuronal Activity. J Neurophysiol American Physiological Society. 2002;87:528-37.

167. Kanemaru K, Sekiya H, Xu M, Satoh K, Kitajima N, Yoshida K, et al. In Vivo Visualization of Subtle, Transient, and Local Activity of Astrocytes Using an Ultrasensitive Ca2 + Indicator. Cell Rep. 2014;8:311-8.

168. Bazargani N, Attwell D. Astrocyte calcium signaling: the third wave. Nat Neurosci Nature Publishing Group. 2016;19:182-9.

169. Arizono M, Inavalli WGK, Panatier A, Pfeiffer T, Angibaud J, Levet F, et al. Structural basis of astrocytic Ca 2 + signals at tripartite synapses. Nat Commun Nature Publishing Group. 2020;11:1906.

170. Hassinger TD, Guthrie PB, Atkinson PB, Bennett MVL, Kater SB. An extracellular signaling component in propagation of astrocytic calcium waves. Proc Natl Acad Sci National Academy of Sciences. 1996;93:13268-73.

171. Guthrie PB, Knappenberger J, Segal M, Bennett MVL, Charles AC, Kater SB. ATP Released from Astrocytes Mediates Glial Calcium Waves. J Neurosci Society for Neuroscience. 1999;19:520-8.

172. Bezzi P, Volterra A. A neuron-glia signalling network in the active brain. Curr Opin Neurobiol. 2001;11:387-94.

173. Covelo A, Araque A. Neuronal activity determines distinct gliotransmitter release from a single astrocyte. Bergles DE, editor. eLife. eLife Sciences Publications, Ltd; 2018;7:p. e32237.

174. Bohmbach K, Schwarz MK, Schoch S, Henneberger C. The structural and functional evidence for vesicular release from astrocytes in situ. Brain Res Bull. 2018;136:65-75.

175. Perea G, Araque A. Astrocytes potentiate transmitter release at single hippocampal synapses. Science. 2007;317:1083-6.

176. Panatier A, Vallée J, Haber M, Murai KK, Lacaille J-C, Robitaille R. Astrocytes Are Endogenous Regulators of Basal Transmission at Central Synapses. Cell. 2011;146:785-98.

177. Gómez-Gonzalo M, Navarrete M, Perea G, Covelo A, Martín-Fernández M, Shigemoto $R$, et al. Endocannabinoids Induce Lateral Long-Term Potentiation of Transmitter Release by Stimulation of Gliotransmission. Cereb Cortex Oxford Academic. 2015;25:3699-712.

178. Mu Y, Bennett DV, Rubinov M, Narayan S, Yang C-T, Tanimoto M, et al. Glia Accumulate Evidence that Actions Are Futile and Suppress Unsuccessful Behavior. Cell. 2019;178:27-43.e19.

179. Martin-Fernandez M, Jamison S, Robin LM, Zhao Z, Martin ED, Aguilar J, et al. Synapse-specific astrocyte gating of amygdala-related behavior. Nat Neurosci. 2017;20:1540-8

180. Fiacco TA, McCarthy KD. Intracellular astrocyte calcium waves in situ increase the frequency of spontaneous AMPA receptor currents in CA1 pyramidal neurons. J Neurosci Off J Soc Neurosci. 2004;24:722-32.

181. Suh J, Jackson FR. Drosophila Ebony Activity Is Required in Glia for the Circadian Regulation of Locomotor Activity. Neuron. 2007;55:435-47.

182. Peng J-J, Lin S-H, Liu Y-T, Lin H-C, Li T-N, Yao C-K. A circuit-dependent ROS feedback loop mediates glutamate excitotoxicity to sculpt the Drosophila motor system. eLife. 2019;8.

183. Jackson FR, You S, Crowe LB. Regulation of rhythmic behaviors by astrocytes. Wiley Interdiscip Rev Dev Biol. 2020;9:e372.

184. Shigetomi E, Jackson-Weaver O, Huckstepp RT, O'Dell TJ, Khakh BS. TRPA1 Channels Are Regulators of Astrocyte Basal Calcium Levels and Long-Term Potentiation via Constitutive d-Serine Release. J Neurosci Society for Neuroscience. 2013:33:10143-53.

185. Bekar LK, He W, Nedergaard M. Locus coeruleus alpha-adrenergic-mediated activation of cortical astrocytes in vivo. Cereb Cortex N Y N 1991. 2008;18: 2789-95.

186. Takata N, Hirase H. Cortical Layer 1 and Layer 2/3 Astrocytes Exhibit Distinct Calcium Dynamics In Vivo. PLoS ONE. 2008;3

187. Takata N, Mishima T, Hisatsune C, Nagai T, Ebisui E, Mikoshiba K, et al. Astrocyte Calcium Signaling Transforms Cholinergic Modulation to Cortical Plasticity In Vivo. J Neurosci Society for Neuroscience. 2011;31: 18155-65.

188. Oe $Y$, Wang $X$, Patriarchi T, Konno A, Ozawa K, Yahagi K, et al. Distinct temporal integration of noradrenaline signaling by astrocytic second messengers during vigilance. Nat Commun Nature Publishing Group. 2020; 11:471.

189. Navarrete M, Cuartero MI, Palenzuela R, Draffin JE, Konomi A, Serra I, et al. Astrocytic p38a MAPK drives NMDA receptor-dependent long-term depression and modulates long-term memory. Nat Commun Nature Publishing Group. 2019;10:2968.

190. Adamsky A, Kol A, Kreisel T, Doron A, Ozeri-Engelhard N, Melcer T, et al. Astrocytic Activation Generates De Novo Neuronal Potentiation and Memory Enhancement. Cell Elsevier. 2018;174:59-71.e14

191. Falcón-Moya R, Pérez-Rodríguez M, Prius-Mengual J, Andrade-Talavera Y, Arroyo-García LE, Pérez-Artés $R$, et al. Astrocyte-mediated switch in spike timing-dependent plasticity during hippocampal development. Nat Commun Nature Publishing Group. 2020;11:4388.

192. Manninen T, Saudargiene A, Linne M-L. Astrocyte-mediated spike-timingdependent long-term depression modulates synaptic properties in the developing cortex. PLOS Comput Biol Public Library of Science. 2020;16: e1008360.

193. Min R, Nevian T. Astrocyte signaling controls spike timing-dependent depression at neocortical synapses. Nat Neurosci. 2012;15:746-53.

194. Mederos S, Sánchez-Puelles C, Esparza J, Valero M, Ponomarenko A, Perea G. GABAergic signaling to astrocytes in the prefrontal cortex sustains goaldirected behaviors. Nat Neurosci. Nature Publishing Group; 2020;1-11.

195. Gutwein BM, Shiromani PJ, Fishbein W. Paradoxical sleep and memory: long-term disruptive effects of Anisomycin. Pharmacol Biochem Behav. 1980;12:377-84

196. Vyazovskiy W, Cirelli C, Pfister-Genskow M, Faraguna U, Tononi G. Molecular and electrophysiological evidence for net synaptic potentiation in wake and depression in sleep. Nat Neurosci Nature Publishing Group. 2008;11:200-8.

197. Yoo S-S, Hu PT, Gujar N, Jolesz FA, Walker MP. A deficit in the ability to form new human memories without sleep. Nat Neurosci Nature Publishing Group. 2007;10:385-92.

198. Berger H. Über das Elektrenkephalogramm des Menschen. Arch Für Psychiatr Nervenkrankh. 1929;87:527-70

199. Cebolla AM, Cheron G. Understanding Neural Oscillations in the Human Brain: From Movement to Consciousness and Vice Versa. Frontiers: Front Psychol; 2019. p. 10

200. Kaiser J, Lutzenberger W. Human gamma-band activity: A window to cognitive processing. NeuroReport. 2005;16:207-11.

201. Sohal VS, Zhang F, Yizhar O, Deisseroth K. Parvalbumin neurons and gamma rhythms enhance cortical circuit performance. Nature. 2009;459:698-702.

202. Haydon PG, Blendy J, Moss SJ, Rob Jackson F. Astrocytic control of synaptic transmission and plasticity: a target for drugs of abuse? Neuropharmacology. 2009;56(Suppl 1):83-90.

203. Bellot-Saez A, Cohen G, van Schaik A, Ooi L, Morley JW, Buskila Y. Astrocytic modulation of cortical oscillations. Sci Rep Nature Publishing Group. 2018;8: 11565.

204. Prolo LM, Takahashi JS, Herzog ED. Circadian Rhythm Generation and Entrainment in Astrocytes. J Neurosci Society for Neuroscience. 2005;25: 404-8.

205. Marpegan L, Swanstrom AE, Chung K, Simon T, Haydon PG, Khan SK, et al. Circadian Regulation of ATP Release in Astrocytes. J Neurosci. 2011;31:834250.

206. Brancaccio M, Patton AP, Chesham JE, Maywood ES, Hastings MH. Astrocytes Control Circadian Timekeeping in the Suprachiasmatic Nucleus via Glutamatergic Signaling. Neuron. 2017:93:1420-35.e5.

207. Bojarskaite L, Bjørnstad DM, Pettersen KH, Cunen C, Hermansen GH, Åbjørsbråten KS, et al. Astrocytic Ca2 + signaling is reduced during sleep and is involved in the regulation of slow wave sleep. Nat Commun. 2020;11:3240.

208. Rasmussen R, O'Donnell J, Ding F, Nedergaard M. Interstitial ions: A key regulator of state-dependent neural activity? Prog Neurobiol. 2020;193: 101802.

209. Ingiosi AM, Hayworth CR, Harvey DO, Singletary KG, Rempe MJ, Wisor JP, et al. A Role for Astroglial Calcium in Mammalian Sleep and Sleep Regulation. Curr Biol CB. 2020;30:4373-83.e7.

210. Blum ID, Keleş MF, Baz E-S, Han E, Park K, Luu S, et al. Astroglial Calcium Signaling Encodes Sleep Need in Drosophila. Curr Biol CB. 2020.

211. Davla S, Artiushin G, Li Y, Chitsaz D, Li S, Sehgal A, et al. AANAT1 functions in astrocytes to regulate sleep homeostasis. eLife. 2020;9.

212. Hablitz LM, Gunesch AN, Cravetchi O, Moldavan M, Allen CN. Cannabinoid Signaling Recruits Astrocytes to Modulate Presynaptic Function in the Suprachiasmatic Nucleus. eNeuro. 2020;7. 
213. Carney RSE. Astrocytes Function as an Intermediate for Retrograde Endocannabinoid Signaling in the Suprachiasmatic Nucleus to Influence Circadian Clock Timing. eNeuro. 2020;7.

214. Han X, Chen M, Wang F, Windrem M, Wang S, Shanz S, et al. Forebrain Engraftment by Human Glial Progenitor Cells Enhances Synaptic Plasticity and Learning in Adult Mice. Cell Stem Cell. 2013;12:342-53.

215. Turovsky EA, Braga A, Yu Y, Esteras N, Korsak A, Theparambil SM, et al. Mechanosensory Signaling in Astrocytes. J Neurosci Society for Neuroscience. 2020;40:9364-71.

216. Hu X, Qin S, Huang X, Yuan Y, Tan Z, Gu Y, et al. Region-Restrict Astrocytes Exhibit Heterogeneous Susceptibility to Neuronal Reprogramming. Stem Cell Rep. 2019;12:290-304.

\section{Publisher's Note}

Springer Nature remains neutral with regard to jurisdictional claims in published maps and institutional affiliations.

Ready to submit your research? Choose BMC and benefit from:

- fast, convenient online submission

- thorough peer review by experienced researchers in your field

- rapid publication on acceptance

- support for research data, including large and complex data types

- gold Open Access which fosters wider collaboration and increased citations

- maximum visibility for your research: over $100 \mathrm{M}$ website views per year

At BMC, research is always in progress.

Learn more biomedcentral.com/submissions 